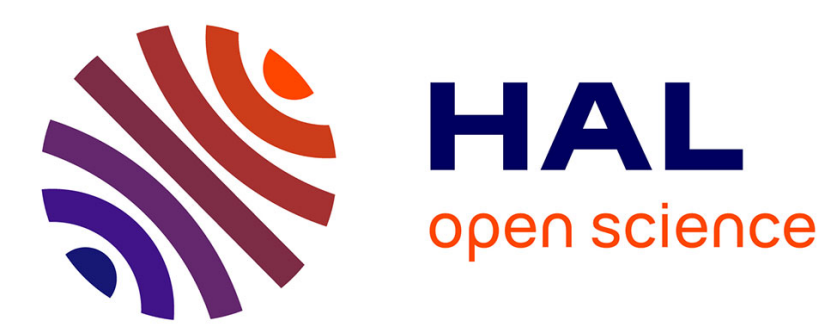

\title{
Evaluation of estimates of crown condition in forest monitoring: comparison between visual estimation and automated crown image analysis
}

Nakajima, Kume, Ishida, Ohmiya, Mizoue

\section{- To cite this version:}

Nakajima, Kume, Ishida, Ohmiya, Mizoue. Evaluation of estimates of crown condition in forest monitoring: comparison between visual estimation and automated crown image analysis. Annals of Forest Science, 2011, 68 (8), pp.1333-1340. 10.1007/s13595-011-0132-9 . hal-00930703

\section{HAL Id: hal-00930703 https://hal.science/hal-00930703}

Submitted on 1 Jan 2011

HAL is a multi-disciplinary open access archive for the deposit and dissemination of scientific research documents, whether they are published or not. The documents may come from teaching and research institutions in France or abroad, or from public or private research centers.
L'archive ouverte pluridisciplinaire HAL, est destinée au dépôt et à la diffusion de documents scientifiques de niveau recherche, publiés ou non, émanant des établissements d'enseignement et de recherche français ou étrangers, des laboratoires publics ou privés. 


\title{
Evaluation of estimates of crown condition in forest monitoring: comparison between visual estimation and automated crown image analysis
}

\author{
Haruki Nakajima • Atsushi Kume • Megumi Ishida • \\ Tohru Ohmiya • Nobuya Mizoue
}

Received: 15 March 2011 /Accepted: 26 August 2011 /Published online: 22 September 2011

(C) INRA and Springer Science+Business Media B.V. 2011

\begin{abstract}
- Context In long-term forest monitoring, tree crown condition has been visually rated to diagnose tree vigor and forest condition. However, visual estimates are subjective. A semiautomatic image analysis system, called CROCO, was developed to estimate crown condition quantitatively. CROCO calculates a DSO value which decrease with increasing crown transparency.
\end{abstract}

\section{Handling Editor: Gilbert Aussenac}

Contribution of the co-authors Writing the manuscript and running the data analysis: Haruki Nakajima and Atsushi Kume

Setting the monitoring program: Megumi Ishida

Conducting the field research: Haruki Nakajima, Megumi Ishida and

Tohru Ohmiya

Adviser on data analysis: Nobuya Mizoue

H. Nakajima $(\bowtie) \cdot$ T. Ohmiya

Toyama Prefectural Agricultural, Forestry and Fisheries Research

Center, Forestry Research Institute,

3 Yoshimine,

Tateyama-machi, Toyama 930-1362, Japan

e-mail: nakajima@fes.pref.toyama.jp

\section{A. Kume}

Ashoro Research Forest, Department of Agro-environmental

Sciences, Kyushu University,

1-85 Kita-5jo,

Ashoro, Hokkaido 089-3705, Japan

M. Ishida

Gifu Field Science Center, Faculty of Applied Biological

Sciences, Gifu University,

1-1 Yanagido,

Gifu 501-1193, Japan

\section{N. Mizoue}

Department of Agro-environmental Sciences,

Kyushu University,

6-10-1 Hakozaki,

Higashi-ku, Fukuoka 812-8581, Japan
- Aims This study aims to verify visual estimates objectively using CROCO and to assess characteristics of visual estimates and DSO values by comparing the effectiveness as indicators of radial growth.

- Methods Crown condition of Abies mariesii was visually rated using a vitality index, and DSO values of the same trees were calculated.

- Results When the top of the tree was intact, the trees with a higher vitality index showed a significantly higher DSO. Vitality index showed the strongest relationship with DBH increment for 8 years. DSO had a significant relationship with DBH increment by adding information of the crown top condition.

- Conclusion Analysis of tree crown images is effective to verify visual estimates. Vitality index is a synthetic index involving factors affecting radial growth. DSO could be utilized similarly to vitality index, as an indicator of radial growth, by addition of information on crown size and/or shape.

Keywords Crown condition · Visual estimation - Image analysis $\cdot \mathrm{CROCO} \cdot$ Crown transparency $\cdot$ Abies mariesii

\section{Introduction}

The importance of long-term ecological research on forest ecosystems is widely recognized, in order to understand the ecosystem itself and to assess the influence of global environmental change. Such monitoring activities are indispensable to detect changes in the ecosystem and biological diversity and have been conducted in a variety of forest ecosystems worldwide (e.g., Hobbie et al. 2003; Feeley et al. 2007).

On Mt. Tateyama, located in the Northern Japan Alps (ca. 3,000 $\mathrm{m}$ a.s.1.), the Tateyama-Kurobe Alpine route was 
opened in 1971. The route was built in the ChubuSangaku National Park and the Bijo-daira (977 m a.s.1.) to Murodo $(2,450 \mathrm{~m}$ a.s.l.) line passes through old forests and highland wetlands. Therefore, it was foreseen that the route would have harmful effects on the natural environment. Several forest monitoring activities have been conducted to assess the effects of the road on the surrounding trees (Kawano 1999). Since 1998, the Mt. Tateyama Vegetation Monitoring Program has examined the influence of environmental changes on the forests, and 10 permanent monitoring plots were established in different forest types on and around $\mathrm{Mt}$. Tateyama (Toyama Prefecture 2008; Kume et al. 2009).

In long-term forest monitoring, a permanent plot method is most widely used, and in many cases, the size and species of every tree in the quadrat are recorded repeatedly over time. The diameter growth rate, mortality, recruitment, and change in species composition are obtained based on the repeated measurements. These measurements are quantitative, and the data obtained are objective and can be acquired with high accuracy, regardless of time and researcher. However, because such information is largely limited to indicating changes in the number and quantity of stems, more detailed information, such as tree crown condition, has been recorded to diagnose tree vigor and forest condition. For example, within the International Co-operative Programme on Assessment and Monitoring of Air Pollution Effects on Forests of the United Nations Economic Commission for Europe (ICP Forests), large-scale monitoring of crown condition has been undertaken to assess forest condition since the mid-1980s (ICP Forests 2009). In response to public concerns about possible forest decline due to air pollution, similar monitoring activities have been conducted worldwide, including in Japan (Ministry of the Environment 2002).

Crown transparency (in ICP Forests termed "defoliation") is the main parameter used to describe crown condition in Europe and North America (Dobbertin et al. 2004; ICP Forests 2009). Other related indices, such as degree of injury (Kawano and Katoh 2000), tree decline index (Ministry of the Environment 2002; Forestry Agency 2003), or vitality index (Toyama Prefecture 2008), have been used in Japan. All of these parameters are rated visually with reference to, for example, crown density, foliage mass, branch density, and tree form, and are generally classified into several degrees. Crown transparency is scored according to a sliding scale with 5\% intervals (Ferretti 1998; Dobbertin et al. 2004). Most Japanese systems classify crown condition into five or six degrees (Kawano and Katoh 2000; Ministry of the Environment 2002; Forestry Agency 2003; Toyama Prefecture 2008).
In long-term or large-scale monitoring, it is impossible for one observer to score and record crown condition, so many observers must participate in the monitoring. However, visual estimates are subjective, and several studies have revealed the existence of significant differences in the visual estimates of the same trees among observers within a country (Innes 1988; Ghosh et al. 1995; Mizoue and Dobbertin 2004) and between countries (Ferretti 1998; Mizoue and Dobbertin 2003; Seidling and Mues 2005), even after the observers were trained thoroughly. Therefore, it is desirable to verify the deterioration of data quality and lack of comparability in the visual estimates by objective measurement.

Fixed-point photography of crowns and application of image processing techniques provide more objective data (Lee et al. 1983; Mizoue and Masutani 1994). Mizoue (2002) developed a semiautomatic image analysis system, called CROCO, to estimate crown condition quantitatively from images photographed from the ground. CROCO calculates a DSO value, which is defined as the difference between the fractal dimension of the silhouette of a tree crown (Ds) and the fractal dimension of its outline (Do). DSO values decrease with increasing crown transparency, and this relationship is represented well by an exponential function with ten conifers and nine broadleaved trees (Mizoue 2001). CROCO has been used for objective verification of visual crown transparency in Europe (Mizoue and Dobbertin 2003, 2004; Dobbertin et al. 2005; Martin-Garcia et al. 2009), but no such studies in Japan have been reported.

Visual estimates of crown condition has been used as an important indicator of tree vigor, and many studies have related such visual estimates to radial growth (e.g., Innes and Cook 1989; Solberg 1999; Yoshida and Mizoue 2003; Dobbertin 2005; Drobyshev et al. 2007). However, few studies have related DSO calculated by CROCO to radial growth (Mizoue and Masutani 2003), and no attempt has been made to compare visual estimates with DSO in relation to radial growth. Such research is required to assess the relative advantage and characteristics of DSO in comparison with visual estimates and to consider how to apply the results of visual estimation and image analysis to evaluate crown condition.

In this study, crown condition of Abies mariesii at Mimatsu on Mt. Tateyama were rated visually using the vitality index (VT), and the DSO of the same trees was calculated using CROCO. We first clarified the relationship between DSO and VT and verified VT objectively. Second, the effectiveness as an indicator of radial growth was compared between VT and DSO. Finally, we considered the relative advantage or disadvantage of visual estimation and image analysis and their application for forest monitoring. 


\section{Materials and methods}

\subsection{Study site and DBH measurement}

The study site, Mimatsu (36 $34^{\prime} 13^{\prime \prime}$ N, 137033'34" E, 1,960 m a.s.l.), is located in the subalpine zone on the west-facing slope of Mt. Tateyama, in the Northern Japan Alps. At Matsuotouge (1,970 m a.s.1.), $1.5 \mathrm{~km}$ from Mimatsu, the annual mean temperature is $3.7^{\circ} \mathrm{C}$ (Toyama Prefecture 2008). This area is very snowy (Mori and Hasegawa 2007; Mori and Mizumachi 2009), and the maximum snow depth exceeds $4 \mathrm{~m}$.

A $100 \times 50$-m permanent plot was established in 1999 by the Tateyama Vegetation Monitoring Program (Toyama Prefecture 2008). The slope angle of the plot was about $20^{\circ}$. Measurements were carried out in 1999 and 2007. All stems greater than $10 \mathrm{~cm}$ in diameter at breast height $(\mathrm{DBH})$ were identified with aluminum numbered tags, which were fixed at the breast height by nails and wires and DBH measured to the nearest $0.1 \mathrm{~cm}$ at the height of the tags. The location of each tree was also recorded. The basal area and stem density were $25.5 \mathrm{~m}^{2} \mathrm{ha}^{-1}$ and 440 stems per hectare in 1999 and $25.8 \mathrm{~m}^{2} \mathrm{ha}^{-1}$ and 444 stems per hectare in 2007, respectively (Toyama Prefecture 2008). A. mariesii was the dominant species and in 1999 occupied $90 \%$ of the basal area, while Betula ermanii occupied $10 \%$ of the basal area. The total stem number of $A$. mariesii in the plot was 185 in 1999 and 182 in 2007, respectively.

\subsection{Sample trees}

In June 2008, 40 trees of $A$. mariesii were selected in the plot. To analyze crown condition using the image analysis system CROCO, we selected trees for which most of the crown did not overlap visually with adjacent trees. The selection was straightforward, because the plot was not a closed stand. The DBH of the sample trees in 1999 was $33.7 \pm 10.2 \mathrm{~cm}$ (mean \pm SD) and ranged from 11.9 to $51.3 \mathrm{~cm}$. The DBH in 2007 was
$35.3 \pm 9.7 \mathrm{~cm}$ and DBH increment from 1999 to 2007 was $1.6 \pm 0.9 \mathrm{~cm}$ (mean $\pm \mathrm{SD})$.

\subsection{Calculation of DSO values by CROCO}

To acquire images for analysis with $\mathrm{CROCO}$, the tree crowns were photographed on 9 June 2008 (Fig. 1), when the understory vegetation was still covered by lingering snow and new needles of $A$. mariesii did not flush yet. Two compact digital cameras, camera A (Optio W10, PENTAX; 6 megapixels) and camera B ( $\mu 710$, OLYMPUS; 7 megapixels), were used. Three images per tree were captured with each camera at the same position, so that six images per tree were obtained. The exposure and focus were set using the automatic setting. The photographs were taken with viewing angles from the ground of less than $45^{\circ}$, because Mizoue (2002) reported that DSO was relatively constant at such angles.

The DSO of the acquired images was calculated with CROCO-Win version 1.10 (ftp://ftp.wsl.ch/downloads/ nobis/CROCO-WIN-setup.zip) as follows (Mizoue 2002). First, for all images, a rectangular region of interest was cut out, excluding the parts overlapping with adjacent trees. The overlap rate was categorized into eight classes (no overlap, $25 \%, 50 \%, 75 \%$, or $100 \%$ overlap on one side of the crown and $25 \%, 50 \%$, or $75 \%$ overlap on both sides). Since we could select sample trees for which most of the crown did not overlap visually with adjacent trees, the sample trees were classified ultimately into five classes (no overlap, $25 \%, 50 \%$, or $75 \%$ overlap on one side and $25 \%$ overlap on both sides). Second, an automatic thresholding algorithm was applied to the blue-filtered gray-scale image to generate the crown silhouette image (Mizoue and Inoue 2001). Finally, the DSO values were calculated from the silhouette images using fractal analysis (Mizoue 2001). The exclusion of those outer parts of the crown that overlapped with other trees results in a positive bias of the DSO value (underestimation of crown transparency), since the outer part
Fig. 1 Examples of images analyzed by CROCO. a $\mathrm{DSO}=0.141, \mathrm{VT}=\mathrm{f} 2$, $\mathrm{CT}=$ top-loss, $\mathbf{b} \mathrm{DSO}=0.050$, $\mathrm{VT}=\mathrm{f} 2, \mathrm{CT}=$ top-intact, $\mathbf{c}$ $\mathrm{DSO}=0.105, \mathrm{VT}=\mathrm{f} 4$, $\mathrm{CT}=$ top-intact, $\mathbf{d}$ $\mathrm{DSO}=0.151, \mathrm{VT}=\mathrm{f} 5$, $\mathrm{CT}=$ top-intact (a)

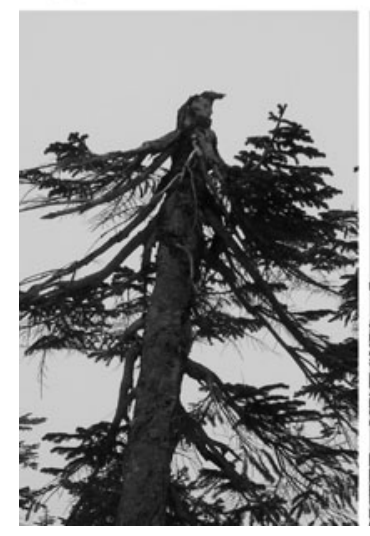

(b)

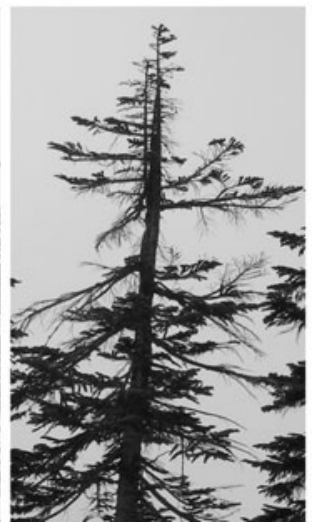

(c)

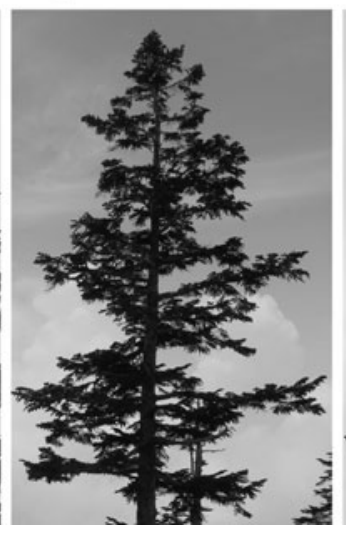

(d)

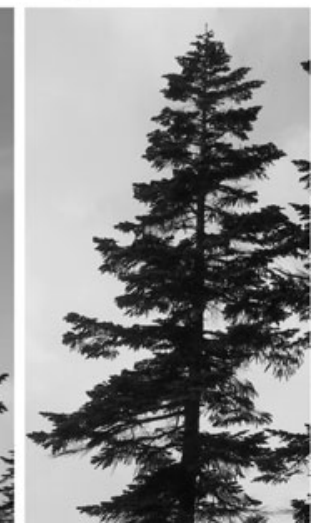


of the two-dimensional silhouette of a crown is generally more transparent. This bias was removed using the simple linear regression model developed by Mizoue (2002).

In four of the 40 sample trees, some differences in DSO values between the three images taken with camera $A$ and those with camera $\mathrm{B}$ were significant $(t$ test, $P<0.05$ ) (Fig. 2). However, no systematic bias existed between the cameras (Fig. 2), so the DSO value of each tree was defined as the average of the six DSO values (e.g. Fig. 1). This value ranged from 0.040 to 0.288 , and the $95 \%$ confidence interval was $0.029 \pm 0.023$ (mean $\pm \mathrm{SD}$ ).

\subsection{Visual estimation of crown condition}

with the vitality index

The crown condition of the trees in the plot were rated visually using the vitality index (VT; Table 1, e.g. Fig. 1) by mutual agreement of two or three observers when the DBH of the sample trees was measured in 2007. The VT was categorized visually into five classes, f1 to f5, which represented deviance of the foliage biomass of a tree from the maximum foliage biomass of a tree with the same DBH. This indicates that VT is similar to "defoliation" which is adopted widely in Europe and defined as needle/leaf loss in the assessable crown as compared to a reference tree (ICP Forests 2010). Both of VT and defoliation express different levels of foliage loss, while VT is described as the ordinal scale of the five classes and defoliation is scored as the ratio scales from $0 \%$ to $100 \%$. The VT of the sample trees ranged from $\mathrm{f} 2$ to $\mathrm{f} 5$. Sample trees of $\mathrm{f} 2$ and $\mathrm{f} 3$ were rare, so these trees were all treated as $\mathrm{f} 23$ in the data analysis (Table 1).

\subsection{Condition of the crown top}

Losses in the crown tops were observed in the sample trees and assumed to be caused by snow stress (Seki et al. 2005).

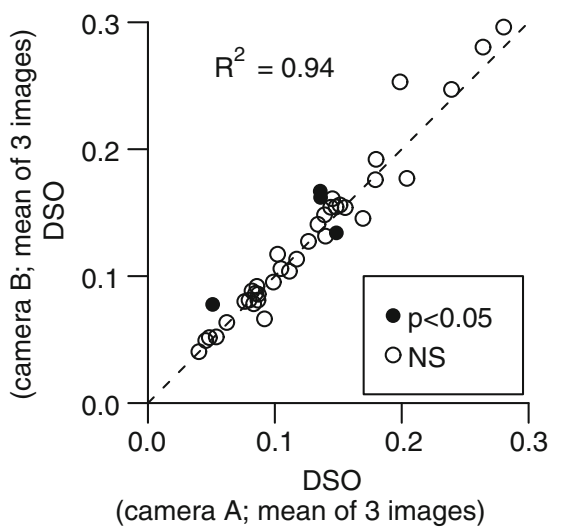

Fig. 2 Comparison of DSO values derived from two cameras. The dashed line indicates a 1:1 relationship, and symbols indicate significance at the $5 \%$ level based on a $t$ test
Even if VT was of the same class, in some trees, the crown top was lost (e.g. Fig. 1a) and in other trees, the crown top was intact (e.g. Fig. 1b). To take into account the condition of the crown top (CT) in the data analysis, the sample trees were distinguished accordingly into two classes, "top-loss" and "top-intact," using images analyzed with CROCO. Eight trees were classified as top-loss, and their VT was f23 except for one tree (Table 1).

\subsection{Data analysis}

To clarify the relationship between VT and DSO, the differences in DSO among VT classes were examined using the Kruskal-Wallis test, followed by pairwise comparisons using the Mann-Whitney $U$ test with Bonferroni-Holm correction. The $\mathrm{f} 23$ class, which included some top-loss trees and some top-intact trees, was divided into two classes, f23-loss and f23-intact, based on CT. Thus, in this analysis, the sample trees were categorized into four classes (f23-loss, f23-intact, f4, and f5). The statistical level of significance used was $P<0.05$. In addition, except for the top-loss trees, Spearman's rank correlation coefficient between VT and DSO was calculated.

To examine the effectiveness of VT and DSO as indicators of radial growth, four linear regression models with different independent variables were developed. The DBH increment from 1999 to 2007 was used as the dependent variable. The independent variables were as follows: DBH (model A); DBH and VT (model $\mathrm{B})$; DBH and DSO (model C); and DBH, DSO, and CT (model D). Dummy variables were used for VT and CT. Akaike's information criterion (AIC) was used to compare models. Smaller AIC values indicate better models. The influences of independent variables were considered significant at $P<0.05$.

All statistical analyses were conducted using $\mathrm{R}$ version 2.8.1 (R Development Core Team 2008).

\section{Results}

\subsection{Relationship between VT and DSO}

The DSO differed significantly among the four classes (Fig. 3; Kruskal-Wallis test). The DSO of the f23-loss trees was high and did not differ significantly from that of the f5 trees $(U$ test). Except for the f23-loss trees, the trees with higher VT had significantly higher DSO values ( $U$ test) and Spearman's rank correlation between VT and DSO was 0.65 $(P<0.001)$. Threshold VT values using DSO were determined by minimizing the ratio of false discrimination. The determined threshold value between $\mathrm{f} 23$-intact and $\mathrm{f} 4$ trees was 0.07 in DSO, and the threshold value between $\mathrm{f} 4$ and 
Table 1 Vitality index and number of sample trees

\begin{tabular}{|c|c|c|c|c|c|}
\hline \multirow{2}{*}{$\begin{array}{l}\text { Vitality } \\
\text { index }\end{array}$} & \multirow{2}{*}{ Condition } & \multirow{2}{*}{$\begin{array}{l}\text { Number of } \\
\text { sample trees }\end{array}$} & \multirow{2}{*}{$\begin{array}{l}\text { VT at data } \\
\text { analysis }\end{array}$} & \multicolumn{2}{|c|}{ Number of sample trees } \\
\hline & & & & top-intact & top-loss \\
\hline f 5 & $\begin{array}{l}\text { A vigorous tree with maximal foliage biomass } \\
\text { corresponding to its DBH. }\end{array}$ & 13 & f 5 & 13 & 0 \\
\hline $\mathrm{f} 4$ & $\begin{array}{l}\text { A tree with moderate foliage biomass } \\
\text { corresponding to its } \mathrm{DBH} \text {. }\end{array}$ & 14 & f 4 & 13 & 1 \\
\hline f 3 & $\begin{array}{l}\text { A tree with low foliage biomass corresponding to } \\
\text { its DBH. }\end{array}$ & 8 & & & \\
\hline $\mathrm{f} 2$ & $\begin{array}{l}\text { A decline tree with reduced foliage biomass } \\
\text { corresponding to its } \mathrm{DBH} \text {. }\end{array}$ & 5 & f 23 & 6 & 7 \\
\hline $\mathrm{f} 1$ & $\begin{array}{l}\text { A conspicuous decline tree with remarkably } \\
\text { lower foliage biomass corresponding to its DBH. }\end{array}$ & - & - & - & - \\
\hline
\end{tabular}

$V T$ vitality index

f5 trees was 0.13 . The ratio of false discrimination was $24 \%$ with the f23-loss trees excluded.

\subsection{Models of radial growth}

The four models of DBH increment with different independent variables are shown in Table 2. The regression coefficient of DBH was significantly negative in all models. The best model was model $\mathrm{B}$, for which $\mathrm{DBH}$ and VT were independent variables. In this model, the regression coefficients of $\mathrm{f} 23$ and $\mathrm{f} 4$ were significantly negative, which revealed that the $\mathrm{f} 23$ and $\mathrm{f} 4$ trees were less vigorous than the f5 trees. In model $\mathrm{C}$ (including $\mathrm{DBH}$ and DSO), the regression coefficient for DSO was not significant. In addition, model $\mathrm{C}$ performed worse than model $\mathrm{A}$ (including DBH only). In contrast, model D (including DBH, DSO, and $\mathrm{CT}$ ) performed better than model $\mathrm{A}$, and the regression coefficient for DSO was significant. This model revealed that the trees with higher DSO were more vigorous, and the toploss trees were less vigorous than the top-intact trees.

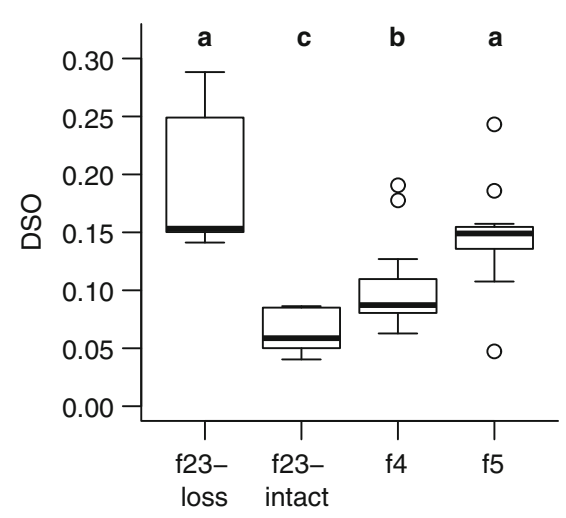

Fig. 3 Box plot of the DSO values of four classes categorized by VT and CT. Different letters above each box indicate a significant difference between classes. Median (central thick lines), 25\% and $75 \%$ percentiles (represented by the box height), upper and lower limits (error bars) and extreme values (circles) are shown

\section{Discussion}

\subsection{Relationship between VT and DSO}

VT was rated visually on the basis of foliage biomass corresponding to the DBH (Table 1) and considers both foliage density and crown size that include CT. The DSO calculated by CROCO evaluates foliage density (Mizoue and Masutani 2003), and crown size was not included in the estimate. Thus, the scopes of the estimates were different between VT and DSO. This is the basic reason for the significant difference in DSO between f23-loss trees and f23intact trees despite possessing the same VT (Fig. 3).

The DSO of the top-loss trees was high regardless of lower VT and did not differ from that of the f5 trees representing the highest VT (Fig. 3). This finding might indicate that the foliage density in the top-loss trees increased in compensation for their injury and in reaction to release from self-shading, reflecting the high morphological plasticity of A. mariesii (Mori and Hasegawa 2007; Mori and Mizumachi 2009). Another possibility is that the proportions of stems and larger branches were remarkably high in the images of top-loss trees (e.g., Fig. 1a). These parts were transformed to black together with the foliage when generating the crown silhouette image, and consequently the calculated DSO was high.

Except for the top-loss trees, the trees with higher VT showed a significantly higher DSO (Fig. $3 ; r=0.65$ ). In addition, VT could be distinguished from DSO quantitatively, but the ratio of false discrimination was $24 \%$. This error would be partly caused by the subjectivity of VT. In this way, visual estimates of crown condition can be verified objectively using CROCO. In Europe, some previous studies compared visually rated crown transparency (defoliation) with estimates calculated by CROCO (Mizoue and Dobbertin 2003, 2004; Dobbertin et al. 2005; Martin-Garcia et al. 2009). For example, Mizoue and Dobbertin (2004) showed that medians of the Spearman's rank correlation coefficients between CROCO and visual 
Table 2 Results of four linear regression models using DBH increment as the dependent variable

\begin{tabular}{llllrrrr}
\hline Model & \multirow{2}{*}{ AIC } & $R^{2}$ & Independent variable & Coefficient & SRC & $P$ value & Partial $R^{2}$ a \\
\hline Model A & \multirow{2}{*}{99.0} & \multirow{2}{*}{0.188} & Intercept & 2.952 & & $<\mathbf{0 . 0 0 1}$ & \\
& & & DBH & -0.039 & -0.434 & $\mathbf{0 . 0 0 5}$ & 0.188 \\
Model B & \multirow{2}{*}{92.4} & \multirow{2}{*}{0.377} & Intercept & 3.164 & & $<\mathbf{0 . 0 0 1}$ & \\
& & & DBH & -0.029 & -0.327 & $\mathbf{0 . 0 2 3}$ & 0.136 \\
& & & VT (f23) & -0.763 & -0.416 & $\mathbf{0 . 0 1 3}$ & 0.159 \\
& & & VT (f4) & -0.864 & -0.480 & $\mathbf{0 . 0 0 4}$ & 0.210 \\
Model C & \multirow{2}{*}{99.5} & \multirow{2}{*}{0.218} & Intercept & 2.632 & & $<\mathbf{0 . 0 0 1}$ & \\
& & & DBH & -0.039 & -0.434 & $\mathbf{0 . 0 0 5}$ & 0.194 \\
& & & DSO & 2.521 & 0.173 & 0.241 & 0.037 \\
Model D & \multirow{2}{*}{95.3} & \multirow{2}{*}{0.331} & Intercept & 2.093 & & $<\mathbf{0 . 0 0 1}$ & \\
& & & DBH & -0.029 & -0.327 & $\mathbf{0 . 0 2 8}$ & 0.127 \\
& & & DSO & 5.488 & 0.377 & $\mathbf{0 . 0 2 4}$ & 0.134 \\
& & & CT (top-loss) & -0.874 & -0.407 & $\mathbf{0 . 0 1 9}$ & 0.144 \\
\hline
\end{tabular}

estimates of five teams were $0.748-0784$ for 2 years and Martin-Garcia et al. (2009) showed that the $R^{2}$ value between CROCO and visual estimates was 0.64 . However, if a visual estimate includes not only foliage density but also crown size, just like the VT, it should be noted that the visual estimate does not always correspond to DSO without information on the crown size, such as CT, and it is useful if the visual estimate is divided into two components, namely foliage density and crown size, in order to improve the correspondence between the visual estimate and DSO.

\subsection{Effectiveness as an indicator of radial growth}

Many previous studies have shown a relationship exists between visual estimates of crown condition and radial growth (e.g., Innes and Cook 1989; Solberg 1999; Yoshida and Mizoue 2003; Dobbertin 2005; Drobyshev et al. 2007). Similarly, visually rated VT was a significant variable for DBH increment in model B, and this model showed that the trees with the highest VT (f5) were more vigorous than the trees with a lower VT (Table 2).

We compared visually rated VT with DSO calculated by $\mathrm{CROCO}$ as an indicator of radial growth using DBH increment data as a dependent variable. The bestperforming model was model B using DBH and VT as the independent variables, and the worst-performing model was model $\mathrm{C}$ using DBH and DSO (Table 2). Model D, which added $\mathrm{CT}$ to model $\mathrm{C}$, also performed worse than model $\mathrm{B}$ (Table 2). Thus, visually rated VT is effective and stable as an indicator of radial growth in comparison with DSO, even if the trees show large differences in the condition of the crowns, such as the top-loss and top-intact trees. This result indicates that VT is a synthetic index that involves factors affecting radial growth, such as crown shape, crown size, and foliage density, as is obvious from its definition (Table 1).
Ferretti et al. (1998) reviewed previous work on visual crown transparency and pointed out that simple crown transparency data were quite crude and that proper interpretation of tree condition needs additional information. The same can be said for DSO, because there are strong relationships $\left(R^{2}=0.942 \pm 0.061(\right.$ mean $\pm \mathrm{SD})$ for 19 species) between DSO and crown transparency when using standard photographs for visual assessments (Mizoue 2001). Actually, DSO was not a significant predictor for DBH increment in model C, but in contrast, DSO was a significant predictor in model $\mathrm{D}$ in which $\mathrm{CT}$ was added to model C (Table 2). In other words, DSO, which is a measure of foliage density (Mizoue and Masutani 2003), could be utilized similarly to VT as an indicator of radial growth, by adding CT to provide information on crown size. Mizoue and Masutani (2003) showed that stem volume increment of Japanese cypress had a strong linear relationship $\left(R^{2}=0.934-0.939\right.$ for two stands) with the product of DSO and crown surface area. Therefore, the usefulness of DSO as an indicator of radial growth is enhanced by adding quantitative data on crown size, such as tree height and crown length, instead of categorical data such as CT.

Recently, airborne laser scanning (ALS) has been established as a valuable tool to estimate effective leaf area index (LAIe) (Morsdorf et al. 2006; Solberg et al. 2006, 2009). ALS can be applied to map LAIe for large areas and detect defoliation in terms of estimated changes in LAIe (Solberg et al. 2006). However, an instrument and vegetation-type-specific calibration parameter will have to be applied to ALS derived estimates in any case (Morsdorf et al. 2006; Solberg et al. 2009). This may be a disadvantage for the long-term forest monitoring and reliable ground reference data will be required for calibration. The combination of airborne and portable ground-based 
scanning lidars could potentially allow an accurate estimation of vertical profiles of the leaf area density (Hosoi et al. 2010), which are nearly equivalent to crown transparency. In this context, our current results suggest how to connect between the advanced remote sensing data and radial growth characteristics, though more research is needed to reveal the relationship between crown shape and radial growth.

\subsection{Comparison between visual estimation} and image analysis

The main advantage of visual estimation of crown condition is that it can be conducted over a short time with the aid of binoculars at most. Many previous studies showed a relationship between visual estimates and radial growth (e.g., Innes and Cook 1989; Solberg 1999; Yoshida and Mizoue 2003; Dobbertin 2005; Drobyshev et al. 2007) and between visual estimates and mortality rate (Dobbertin and Brang 2001). The present study revealed that visual estimates were effective as an indicator of radial growth even if including both top-intact and top-loss trees (Table 2). Therefore, visual estimates are indicated to be useful and stable for diagnosis of tree vigor. However, the disadvantage of visual estimation is subjectivity, and the data quality and comparability of assessments have often been questioned (e.g., Mizoue and Dobbertin 2003). By contrast, image analysis can contribute to quantitative and objective estimation, as can be recognized from the general correspondence of DSO values between different cameras (Fig. 2) and is particularly reliable for estimation of foliage density (Mizoue and Masutani 2003). Thus, image analysis can be used for verification of visual estimates (Fig. 3; Mizoue and Dobbertin 2003, 2004; Dobbertin et al. 2005; Martin-Garcia et al. 2009). However, it should be noted that estimates obtained from image analysis do not always correspond with visual estimates and, as mentioned above, are not always a reliable indicator of radial growth without information on crown size.

Another important contrast between visual estimation and image analysis is that visual estimation can be conducted even with bad visibility (Ferretti 1997), whereas the use of image analysis is clearly limited by visibility of the target crown from the ground, especially in closed stands (Mizoue and Masutani 2003). CROCO cannot perform precise estimation if the overlap rate with adjacent trees is larger than about $50 \%$ of the crown width (Mizoue 2002).

\subsection{Recommendation for application of image analysis} in forest monitoring

Estimation of all trees in the monitoring plot should be conducted visually because image analysis is limited by visibility. However, image analysis of subsample trees can be used for objective verification of visual estimates, detection of observer bias among different field teams, and comparison of surveys conducted at different times (Mizoue and Dobbertin 2003). Even if image analysis is not implemented, the images of the visually rated crowns should be conserved for future reference.

Acknowledgments We are grateful to Ms. Yuka Maeda for assistance with the operation of CROCO. Toyama Prefecture and the Toyama District Forest Office granted permission to conduct research on Mt. Tateyama.

Funding This study was supported by Toyama Prefecture and Kyusyu University.

\section{References}

Dobbertin M (2005) Tree growth as indicator of tree vitality and of tree reaction to environmental stress: a review. Eur J For Res 124:319-333. doi:10.1007/s10342-005-0085-3

Dobbertin M, Brang P (2001) Crown defoliation improves tree mortality models. For Ecol Manage 141:271-284. doi:10.1016/ S0378-1127(00)00335-2

Dobbertin M, Hug C, Mizoue N (2004) Using slides to test for changes in crown defoliation assessment methods. Part I: Visual assessment of slides. Environ Monit Assess 98:295-306. doi:10.1023/B:EMAS.0000038192.84631.b6

Dobbertin M, Hug C, Mizoue N (2005) Using slides to test for changes in crown defoliation assessment methods part II: application of the image analysis system CROCO. Environ Monit Assess 102:167-178. doi:10.1007/s10661-005-6019-1

Drobyshev I, Linderson H, Sonesson K (2007) Relationship between crown condition and tree diameter growth in southern Swedish oaks. Environ Monit Assess 128:61-73. doi:10.1007/s10661006-9415-2

Feeley KJ, Wright SJ, Supardi MNN, Kassim AR, Davies SJ (2007) Decelerating growth in tropical forest trees. Ecol Lett 10:461469. doi:10.1111/j.1461-0248.2007.01033.x

Ferretti M (1997) Forest health assessment and monitoring - issues for consideration. Environ Monit Assess 48:45-72. doi:10.1023/ A: 1005748702893

Ferretti M (1998) Potential and limitation of visual indices of tree condition. Chemosphere 36:1031-1036. doi:10.1016/S00456535(97)10167-9

Ferretti M, Baratozzi L, Cenni E, Cozzi A, Savini P (1998) Crown transparency of beech (Fagus sylvatica L.) in the Northern Appennines (Italy) - Status, changes and relationships with site characteristics and other indices of tree condition. Chemosphere 36:1037-1042. doi:10.1016/S0045-6535(97) 10168-0

Forestry Agency (2003) Dai 2 ki sanseiu tou shinrin suitai monitaringu zigyou houkokusyo. Forest Agency, Tokyo (in Japanese)

Ghosh S, Innes JL, Hoffmann C (1995) Observer variation as a source of error in assessments of crown condition through time. For Sci 41:235-254

Hobbie JE, Carpenter SR, Grimm NB, Gosz JR, Seastedt TR (2003) The US long term ecological research program. BioScience 53:21-32. doi:10.1641/0006-3568(2003)053[0021:TULTER]2.0. $\mathrm{CO} ; 2$

Hosoi F, Nakai Y, Omasa K (2010) Estimation and error analysis of woody canopy leaf area density profiles using 3-D airborne and ground-based scanning lidar remote-sensing techniques. IEEE 
Trans Geosci Remote Sens 48:2215-2223. doi:10.1109/ TGRS.2009.2038372

ICP Forests (2009) The condition of forests in Europe. 2009 executive report. United Nations Economic Commision for Europe, Brussels

ICP Forests (2010) Manual on methods and criteria for harmonized sampling, assessment, monitoring and analysis of the effects of air pollution on forests. http://www.icp-forests.org/Manual.htm Accessed 16 July 2011

Innes JL (1988) Forest health surveys: problems in assessing observer objectivity. Can J For Res 18:560-565. doi:10.1139/x88-081

Innes JL, Cook ER (1989) Tree-ring analysis as an aid to evaluating the effects of pollution on tree growth. Can J For Res 19:11741189. doi:10.1139/x89-177

Kawano S (1999) Disturbance and conservation of the subalpinealpine vegetation and biota in the Tateyama-Kurobe National Park, the Japan North Alps in Central Honshu, Japan: The results of long-term monitoring. Jap J Ecol 49:313-320 (in Japanese)

Kawano S, Katoh T (2000) Implications of long-term monitoring on the tree growth exposed to air pollution and an assessment of its effects. Jap J Ecol 50:289-295 (in Japanese)

Kume A, Numata S, Watanabe K, Honoki H, Nakajima H, Ishida M (2009) Influence of air pollution on the mountain forests along the Tateyama-Kurobe Alpine route. Ecol Res 24:821-830. doi:10.1007/s11284-008-0557-2

Lee YJ, Alfaro RI, Van Sickle GA (1983) Tree-crown defoliation measurement from digitized photographs. Can J For Res 13:956961. doi:10.1139/x83-127

Martin-Garcia J, Diez JJ, Jactel H (2009) Towards standardised crown condition assessment in poplar plantations. Ann For Sci 66:308. doi:10.1051/forest/2009006

Ministry of the Environment (2002) Long-term acid deposition monitoring. Ministry of the Environment, Tokyo

Mizoue N (2001) Fractal analysis of tree crown images in relation to crown transparency. J For Plann 7:79-87

Mizoue N (2002) CROCO: semi-automatic image analysis system for crown condition assessment in forest health monitoring. J For Plann 8:17-24

Mizoue N, Dobbertin M (2003) Detecting differences in crown transparency assessments between countries using the image analysis system CROCO. Environ Monit Assess 89:179-195. doi:10.1023/A:1026044701939

Mizoue N, Dobbertin M (2004) Within country accuracy of tree crown transparency estimates using the image analysis system CROCO: a case study from Switzerland. Environ Model Software 19:1089-1095. doi:10.1016/j.envsoft.2003.10.009
Mizoue N, Inoue A (2001) Automatic thresholding of tree crown image. J For Plann 6:75-80

Mizoue N, Masutani T (1994) Fractal on the vertical section form of tree crowns. J Jap For Soc 76:242-248 (in Japanese with English summary)

Mizoue N, Masutani T (2003) Image analysis measure of crown condition, foliage biomass and stem growth relationships of Chamaecyparis obtusa. For Ecol Manage 172:79-88. doi:10.1016/S0378-1127(02)00281-5

Mori A, Hasegawa SF (2007) Structural characteristics of Abies mariesii saplings in a snowy subalpine parkland in central Japan. Tree Physiol 27:141-148. doi:10.1093/treephys/27.1.141

Mori AS, Mizumachi E (2009) Within-crown structural variability of dwarfed mature Abies mariesii in snowy subalpine parkland in central Japan. J For Res 14:155-166. doi:10.1007/s10310-0090115-y

Morsdorf F, Kötz B, Meier E, Itten KI, Allgöwer B (2006) Estimation of LAI and fractional cover from small footprint airborne laser scanning data based on gap fraction. Remote Sens Environ 104:50-61. doi:10.1016/j.rse.2006.04.019

R Development Core Team (2008) R: A language and environment for statistical computing. R Foundation for Statistical Computing, Vienna

Seidling W, Mues V (2005) Statistical and geostatistical modelling of preliminarily adjusted defoliation on an European scale. Environ Monit Asess 101:223-247. doi:10.1007/s10661-005-9304-0

Seki T, Kajimoto T, Sugita H, Daimaru H, Ikeda S, Okamoto T (2005) Mechanical damage on Abies mariesii trees buried below the snowpack. Arct Antart Alp Res 37:34-40. doi:10.1657/15230430(2005)037[0034:MDOAMT]2.0.CO;2

Solberg S (1999) Crown condition and growth relationships within stands of Picea abies. Scand J For Res 14:320-327

Solberg S, Næsset E, Hanssen KH, Christiansen E (2006) Mapping defoliation during a severe insect attack on Scots pine using airborne laser scanning. Remote Sens Environ 102:364-376. doi:10.1016/j.rse.2006.03.001

Solberg S, Brunner A, Hanssen KH, Lange H, Næsset E, Rautiainen M, Stenberg P (2009) Mapping LAI in a Norway spruce forest using airborne laser scanning. Remote Sens Environ 113:23172327. doi:10.1016/j.rse.2009.06.010

Toyama Prefecture (2008) Kankyouhendou to Tateyama no shizen (II) Tateyama shokusei monitaringu dai II ki chousa seika houkokusyo. Toyama Prefectural Government, Toyama (in Japanese)

Yoshida S, Mizoue N (2003) Crown health monitoring for old-trees on the Abies-Tsuga natural forest on Kirishima National Park in Kagoshima pref., Japan (IV). Kyushu. J For Res 56:161-164 (in Japanese) 